\title{
Spatial patterns of functional diversity and composition in marine benthic ciliates along the coast of China
}

\author{
Y. $\mathrm{Xu}^{1, *}$, J. Soininen ${ }^{2}$ \\ ${ }^{1}$ State Key Laboratory of Estuarine and Coastal Research, East China Normal University, Shanghai 200241, P. R. China \\ ${ }^{2}$ Department of Geosciences and Geography, University of Helsinki, Helsinki 00014, Finland
}

\begin{abstract}
Large-scale patterns of community composition and diversity along environmental gradients have been well studied for macroorganisms. However, the biogeography of microorganisms, especially ciliated protozoa, remains understudied. Here, we analyzed a comprehensive database of marine benthic ciliates found along the coast of China from 1991 to 2018 to examine the geographical patterns in species and trait composition and functional diversity. According to redundancy analysis conducted at large spatial scales, environmental variables, i.e. habitat type and salinity, explained more variance in species composition than latitude. In contrast, trait composition was better explained by spatial and climatic variables. At small spatial scales, both species and trait composition were probably influenced by mass effects due to the high dispersal ability of ciliates at such small scales, resulting in spatially homogenized communities. Several traits, including body size, feeding type and mobility, exhibited significant positive or negative latitudinal gradients. Functional diversity showed a significant positive correlation with latitude between 20 and $40^{\circ} \mathrm{N}$, which may be caused by certain groups of ciliates possessing particular traits related to temperature. Our study is the first comprehensive evaluation of how trait composition and functional diversity of marine ciliated protozoa vary at large scales and can thus make a major contribution to the study of microbial biogeography.
\end{abstract}

KEY WORDS: Protist · Spatial ecology $\cdot$ Trait composition $\cdot$ Latitudinal gradients $\cdot$ Mass effects

\section{INTRODUCTION}

Over the past few years, the geographic distribution of microorganisms has become a focus of biogeographic studies (e.g. Dolan et al. 2006, Martiny et al. 2006, Vyverman et al. 2007, Soininen 2012, Azovsky \& Mazei 2013, Soininen et al. 2016). Due to the high dispersal rates and large population sizes of microbes, their spatial distribution patterns and underlying mechanisms may fundamentally differ from those of macroorganisms (Martiny et al. 2006, Soininen 2012). Historically, 2 opposing views about the biogeography of microorganisms have gained great attention: first is the hypothesis of Baas-Becking (1934, p. 15):

${ }^{*}$ Corresponding author: yxu@sklec.ecnu.edu.cn

$\S$ Article was changed to Open Access, and the copyright notice updated after publication.

This corrected version: April 15, 2020 'everything is everywhere, but, the environment selects'. The rationale behind this view is the niche assembly mechanism or species sorting, i.e. species are filtered by environmental factors to occur in suitable conditions. Based on this idea, the cosmopolitan model was suggested by Finlay et al. (1996, 1999), which maintained that the distribution of microbes is fundamentally different from that of macroorganisms and not limited by geographical barriers and distance. The second view is the moderate endemicity model suggested by Foissner (1998, 1999), which postulates that a proportion of microorganisms (e.g. flagship species) have restricted modern geographical distributions, which may reflect their original

() The authors 2020. Open Access under Creative Commons by Attribution Licence. Use, distribution and reproduction are unrestricted. Authors and original publication must be credited.

Publisher: Inter-Research · www.int-res.com 
geographic ranges on ancient continents. A growing number of microbial studies have recently indicated that the relative importance of environmental and spatial variables on microbes depends on study scale and ecosystem types (Langenheder \& Ragnarsson 2007, Martiny et al. 2011, Soininen et al. 2011, Chytrý et al. 2012, Soininen 2012, Heino et al. 2014).

In addition to species distributions, the latitudinal gradient of species richness is one of the most important topics in macroecology of multicellular organisms (Hillebrand 2004). However, studies on latitudinal patterns of microorganisms have been rarer (but see Rutherford et al. 1999, Dolan et al. 2006, Fierer \& Jackson 2006, Vyverman et al. 2007, Fuhrman et al. 2008, Barton et al. 2010, Passy 2010, Azovsky \& Mazei 2013, Soininen et al. 2016). Collectively, these studies have found various relationships between latitude and microbial diversity. For example, Passy (2010) found a U-shaped latitudinal pattern for freshwater diatom diversity in the USA, while a study on the global distribution of lake benthic diatoms revealed a hump-shaped relationship, with the highest diversity detected in a temperate zone (Vyverman et al. 2007). For microbes, the potential drivers of latitudinal diversity patterns include local environmental variables, such as salinity, $\mathrm{pH}$ and habitat availability, and climatic factors, especially temperature (Rutherford et al. 1999, Vyverman et al. 2007, Passy 2010, Azovsky \& Mazei 2013, Soininen et al. 2016).

In addition to taxonomical species composition, there is a growing interest in the spatial patterns of trait composition and functional diversity among microbes (e.g. Green et al. 2008, Soininen et al. 2016). As traits reflect the 'things that organisms do', these can be more directly linked to species fitness or performance than taxonomical identity (Petchey \& Gaston 2006). Moreover, functional diversity considers organisms as dynamic entities that interact with their environment (Calow 1987, Laureto et al. 2015). Therefore, investigating geographical patterns of trait composition and functional diversity as well as their potential driving factors can provide a better understanding of the relationships between communities and environmental conditions (McGill et al. 2006, Villéger et al. 2008, 2011). Consequently, trait-based approaches can make science more predictive and able to forecast ecosystem alterations occurring under rapid environmental changes.

Ciliates, a major group of unicellular eukaryotes, contribute significantly to the quantity and biodiversity of microorganisms and the energetics of microbial communities (Fenchel 1967). Ciliated protozoa have been well characterized taxonomically and functionally compared with other groups of protozoa, which makes it possible to study their spatial patterns using both species and trait composition. However, studies on spatial patterns of ciliate communities at large scales, especially on trait composition and functional diversity, are scarce.

China has a long coastline ranging from the tropics to the temperate zone. These coastal areas are highly heterogeneous, including divergent habitat types such as sandy beaches, rocky reefs, salt marshes and mangroves, which makes it ideal to examine how environmental and spatial factors in concert contribute to shaping ciliate distributions. Our aim was to address the following specific questions: (1) How does benthic ciliate community composition vary along the coast of China at taxonomical and trait levels, and what are the main factors driving its variation? (2) Does the functional diversity of coastal benthic ciliate communities show a latitudinal gradient?

\section{MATERIALS AND METHODS}

\subsection{Database}

The ciliate data were compiled from different sources. The data from the coastlines of the Chinese Bohai Sea, Yellow Sea and South China Sea were obtained from the marine ciliate biodiversity survey conducted by the Laboratory of Protozoology, Ocean University of China, from 1991 to 2018 (Fig. 1). We collected all species found in benthic habitats, i.e. intertidal sandy beach and mangrove, during this period. The data sources include 2 monographs (Song et al. 2009, Hu et al. 2019) and all papers published by the Laboratory of Protozoology, Ocean University of China (for a list of papers, see http://scxy.ouc.edu.cn/lplb/13776/list.htm). Species without specific sampling locations were excluded from the final list. The sampled habitats along the Bohai Sea and Yellow Sea coasts include only sandy beaches, while those along the South China Sea coasts include both sandy beaches and mangroves. For each site, species occurrences include data over the entire time period (1990s-2018) to reduce insufficient sampling effort in each single sample. The Yangtze River estuary data originated from $\mathrm{Xu}$ et al. (2018b). This data set contained 3 sampling sites in salt marsh habitat (Fig. 1). In order to facilitate taxonomic consistency between different data sets, species-level data were as- 

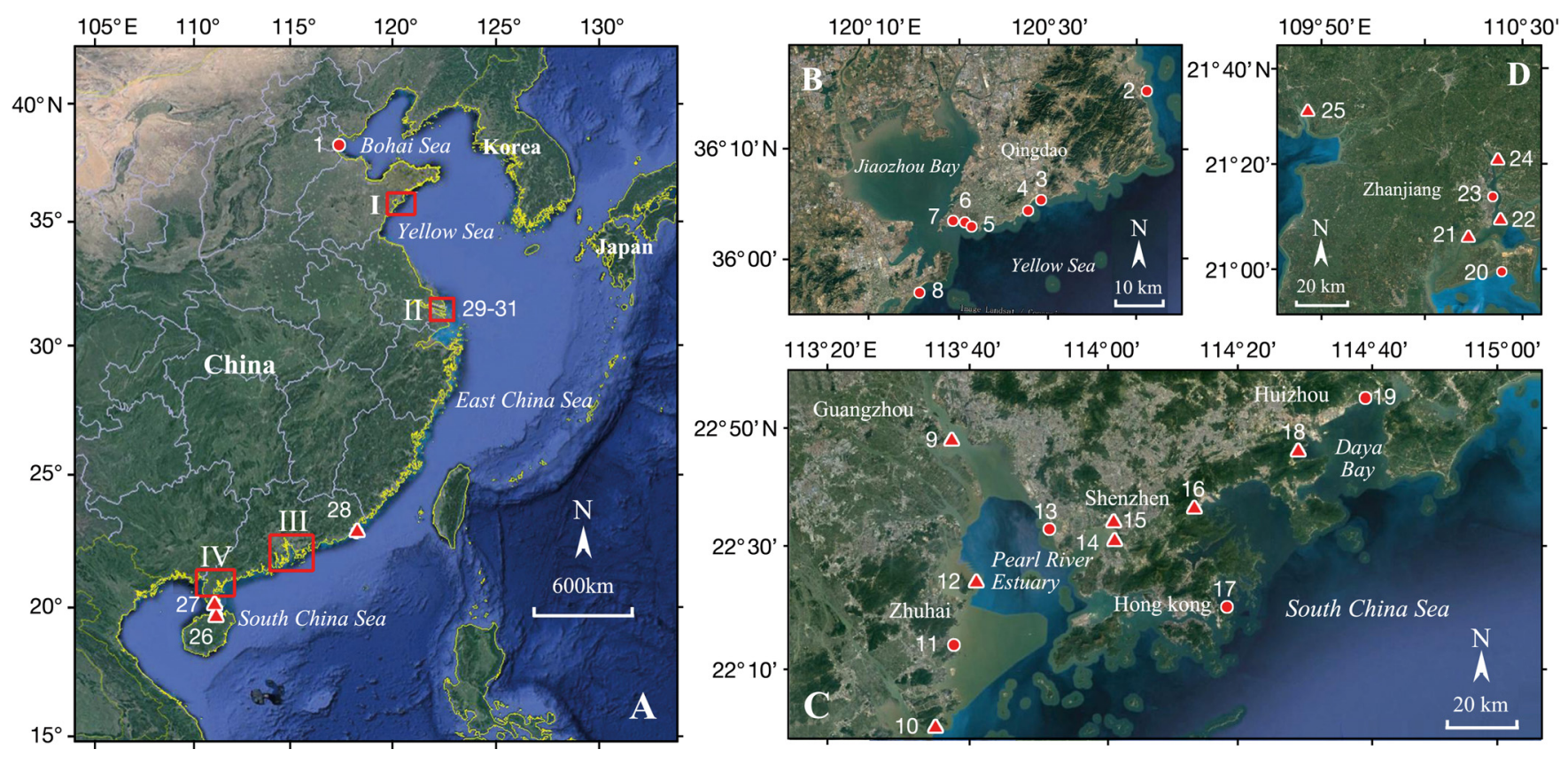

Fig. 1. (A) Locations of the study sites along the coast of China, with detailed locations of the sampling sites within squares (B) I, (C) III and (D) IV. Circles indicate sandy beach habitat and triangles refer to mangrove habitat. Site names are: 1 , Tianjin; 2 , Qingdao_Yangkou; 3, Qingdao_Shilaoren; 4, Qingdao_Diaosuyuan; 5, Qingdao_No. 2; 6, Qingdao_No. 1; 7, Qingdao_Zhanqiao; 8, Qingdao_Jinshatan; 9, Guangzhou; 10, Zhuhai_Hengqin; 11, Zhuhai_Haibin park; 12, Zhuhao_Qiao; 13, Shenzhen_Nanshan; 14, HK_mangrove; 15, Shenzhen_mangrove; 16, Shenzhen_Dameisha; 17, HK_Clear Water Bay; 18, Daya Bay_mangrove; 19, Daya Bay_sandy beach; 20, Zhanjiang_Donghai Island; 21, Zhangjiang_Huguang; 22, Zhanjiang_Techeng Island; 23, Zhangjiang_Haibin Park;24, Zhanjiang_Guandu; 25, Zhanjiang_Gaoqiao; 26, Haikou; 27, Zhanjiang_Haian; 28, Shantou; 29, site $1 ; 30$, site 2; 31, site 3

signed to genus level (presence/absence data) according to the systematic classification (Lynn 2008; see Table S1 in Supplement 1 at www.int-res.com/ articles/suppl/m627p049_supp1.xls for a complete list of the genera encountered), which resulted in a data set comprising 220 ciliate genera collected from 31 sites along the Chinese coast (Fig. 1).

We included 3 local environmental variables: habitat type (4 levels, i.e. North sandy beach, South sandy beach, salt marsh and mangrove), defined as a categorical variable, and 2 water chemistry variables, i.e. salinity and $\mathrm{pH}$, which were averaged for each site (Fig. S1 in Supplement 2 at www.int-res. com/articles/suppl/m627p049_supp2.pdf). We determined latitude for each site using data reported in the original publications and Google Earth. We also included 2 climatic variables (annual mean temperature and annual precipitation) from WorldClim (Hijmans et al. 2005) at $30 \mathrm{~s}$ resolution. Net primary productivity (NPP) was extracted from SEDAC at 0.25 decimal degrees (Imhoff et al. 2004). Salinity, climatic variables and NPP were log-transformed to better approximate normality of residuals, then all variables were standardized before analysis.

\subsection{Trait analysis and functional diversity}

We selected 5 traits sub-divided into 13 categories (Table 1) according to $\mathrm{Xu}$ et al. (2018a). These traits reflect morphological characteristics (body size, degree of flexibility and body form) and behavior (feeding and mobility). Data on traits were mainly obtained from the original sources in which the species were described, as well as from expert opinions and literature (Pratt \& Cairns 1985, Lynn 2008). A fuzzy-coding procedure was used to account for an individual taxon displaying multiple trait categories according to $\mathrm{Xu}$ et al. (2018b). For each community, the trait values were averaged by all species present in a community using the 'FD' package in R 3.5.3 (https://CRAN.R-project.org/ package $=F D_{;}$Laliberté et al. 2014). To measure functional diversity, we used functional divergence (FDiv) since it is independent of sampling effort (Villéger et al. 2008) and has an advantage over other functional diversity indices to infer environmental status (Gusmao et al. 2016, Xu et al. 2018b). FDiv was computed using the 'FD' package in R 3.5.3 (Laliberté et al. 2014). 
Table 1. Functional trait variables and categories used in the current study

\begin{tabular}{|c|c|c|}
\hline Trait & Category & Description \\
\hline \multirow[t]{3}{*}{ Feeding type } & Bacterivores & Feeding on bacteria \\
\hline & Algivores & Feeding on algae \\
\hline & Predators & $\begin{array}{l}\text { Feeding on flagellates } \\
\text { and ciliates }\end{array}$ \\
\hline \multirow{3}{*}{ Body size } & Small & Cell length $<50 \mu \mathrm{m}$ \\
\hline & Medium & $50 \mu \mathrm{m}<$ cell length $<200 \mu \mathrm{m}$ \\
\hline & Large & $200 \mu \mathrm{m}<$ cell length \\
\hline \multirow[t]{3}{*}{ Mobility } & Attached to substrate & Non-mobile \\
\hline & Swimming & Locomotion by swimming \\
\hline & Crawling & $\begin{array}{l}\text { Locomotion by crawling } \\
\text { on substrate }\end{array}$ \\
\hline \multirow[t]{2}{*}{ Body form } & Dorso-ventrally flattened & Ratio of thickness:width $<1: 4$ \\
\hline & Cylindrical & Ratio of thickness:width $>1: 4$ \\
\hline \multirow[t]{2}{*}{ Cell flexibility } & Non-flexible & $\begin{array}{l}\text { Cell non-flexible and } \\
\text { non-contractile }\end{array}$ \\
\hline & Flexible & $\begin{array}{l}\text { Cell either flexible or } \\
\text { contractile or both }\end{array}$ \\
\hline
\end{tabular}

diversity along the coast of China. We started with a full model, and the most parsimonious model was selected based on Akaike's information criterion (AIC). We provide the ANOVA results of the final model. Since the climatic variables were strongly correlated with latitude $(\mathrm{r}>0.85)$, they were excluded from the RDA and GLM.

\section{RESULTS}

\subsection{Variability of water chemistry}

Generally, the ranges of both salinity and $\mathrm{pH}$ in the Yangtze River estuary and southern coastal areas of China were wider compared to those in northern China (Fig. S1). Sites

\subsection{Data analyses}

The genera presence/absence data were Hellinger transformed prior to analysis (Peres-Neto et al. 2006). We analyzed the patterns in species and trait composition with non-metric multidimensional scaling (nMDS) followed by environmental factor fitting to examine the major structure. Permutational multivariate ANOVA (PERMANOVA) was used to determine the significance of differences in species and trait compositions among different habitat types (Anderson et al. 2008). A Bray-Curtis similarity matrix based on species data and a Gowdis distance matrix based on traits data were used for nMDS and PERMANOVA. PERMANOVA was conducted on unrestricted permutation raw data using 999 random permutations. We used tests of homogeneity of dispersion (PERMDISP) to examine dispersion of species and trait composition among the 4 habitat types (Anderson et al. 2008). nMDS PERMANOVA and PERMDISP were performed in PRIMER 7 + PERMANOVA (PRIMER-E). We then used redundancy analysis (RDA) to explain the main patterns in species and trait composition. RDA was applied with forward selection, using Monte Carlo Permutation tests (999 permutations), to select only those variables that significantly explained variation in the benthic ciliate communities among sites. Forward selection and RDA were carried out using the 'packfor' and 'vegan' packages in R (R Development Core Team). Finally, we used generalized linear modeling (GLM) with Gaussian type distribution on square root transformed FDiv to examine the patterns in functional along the Bohai Sea and Yellow Sea were close to typical marine habitat, with salinity around 30 and alkaline $\mathrm{pH}$ values (7.5-8.0). However, sites in the Yangtze River estuary and southern China were more influenced by coastal rivers, so the salinity varied from 0.3 to 33 . In these areas, 16 out of 23 sites were brackish water habitats with salinity ranging from 10 to 25 , and $\mathrm{pH}$ values were mainly alkaline, varying from 7.0 to 8.9 , with only 1 exception where the $\mathrm{pH}$ was 6.3 .

\subsection{Patterns of species composition}

Overall, species composition differed significantly among different habitat types (PERMANOVA, main test, $\mathrm{p}=0.001$; Table 2). However, the difference in species composition between the South sandy beach and the North sandy beach or mangrove was not significant (Table 2).

The wide variation in species compositional heterogeneity was clear in the nMDS plots, which showed that salt marsh sites were closely clustered compared with sites of the other 3 habitat types (Fig. 2A). This pattern was verified by PERMDISP analysis (Table S2). Moreover, based on nMDS analysis, spatial and climatic variables had a strong relationship with species composition on nMDS axis 2, which separated mangrove from the North sandy beach, with the South sandy beach in the middle (Fig. 2A). NPP was correlated with mangrove and salt marsh while salinity was correlated with the North and the South sandy beach 
Table 2. Full output from the 1-factor PERMANOVA by habitat type examining species and trait composition of benthic ciliates along the coast of China. Asterisks indicate significance at ${ }^{*} \mathrm{p}<0.05,{ }^{* *} \mathrm{p}<0.01$

\begin{tabular}{|lcc|}
\hline & $\begin{array}{c}\text { Species } \\
\text { composition }\end{array}$ & $\begin{array}{c}\text { Trait } \\
\text { composition }\end{array}$ \\
\hline Main test & $0.001^{* *}$ & $0.001^{* *}$ \\
Pair-wise test & $0.017^{*}$ & $0.041^{*}$ \\
North sandy beach $\times$ Salt marsh & $0.019^{*}$ & $0.011^{*}$ \\
Salt marsh $\times$ South sandy beach & $0.002^{* *}$ & $0.003^{* *}$ \\
Salt marsh $\times$ Mangrove & 0.122 & $0.022^{*}$ \\
North sandy beach $\times$ South sandy beach & $0.002^{* *}$ & $0.002^{* *}$ \\
North sandy beach $\times$ Mangrove & 0.069 & 0.296 \\
South sandy beach $\times$ Mangrove & & \\
\hline
\end{tabular}

(Fig. 2A). Water $\mathrm{pH}$ correlated notably with nMDS axis 1. A vector overlay of Pearson correlations of the typical genera $(\mathrm{r}>0.5)$ with the axes is shown in Fig. 2B; vectors for 5 genera (i.e. Cinetochilum,
Sathrophilus, Tracheloraphis, Hippocomos and Pseudocohnilembus) were correlated with the North sandy beach; vectors for 3 genera (Cohnilembus, Neourostylopsis and Euplotes) were correlated with the South sandy beach and mangrove; and 1 genus (Loxophyllum) was correlated with salt marsh.

The results from RDA demonstrated that species composition was related significantly to both environmental variables, i.e. habitat type and salinity, and to latitude (Table 3). The total fraction of the variance explained by the separately run RDA was $8.4 \%$ (Adj R ${ }^{2}$ ) and $2.4 \%$ (Adj $\mathrm{R}^{2}$ ) for habitat type and salinity, respectively, while the variance explained by latitude was $2.5 \%$ $\left(\operatorname{Adj} \mathrm{R}^{2}\right.$ ).

Habitat types: $\quad \nabla$ North sandy beach

Mangrove
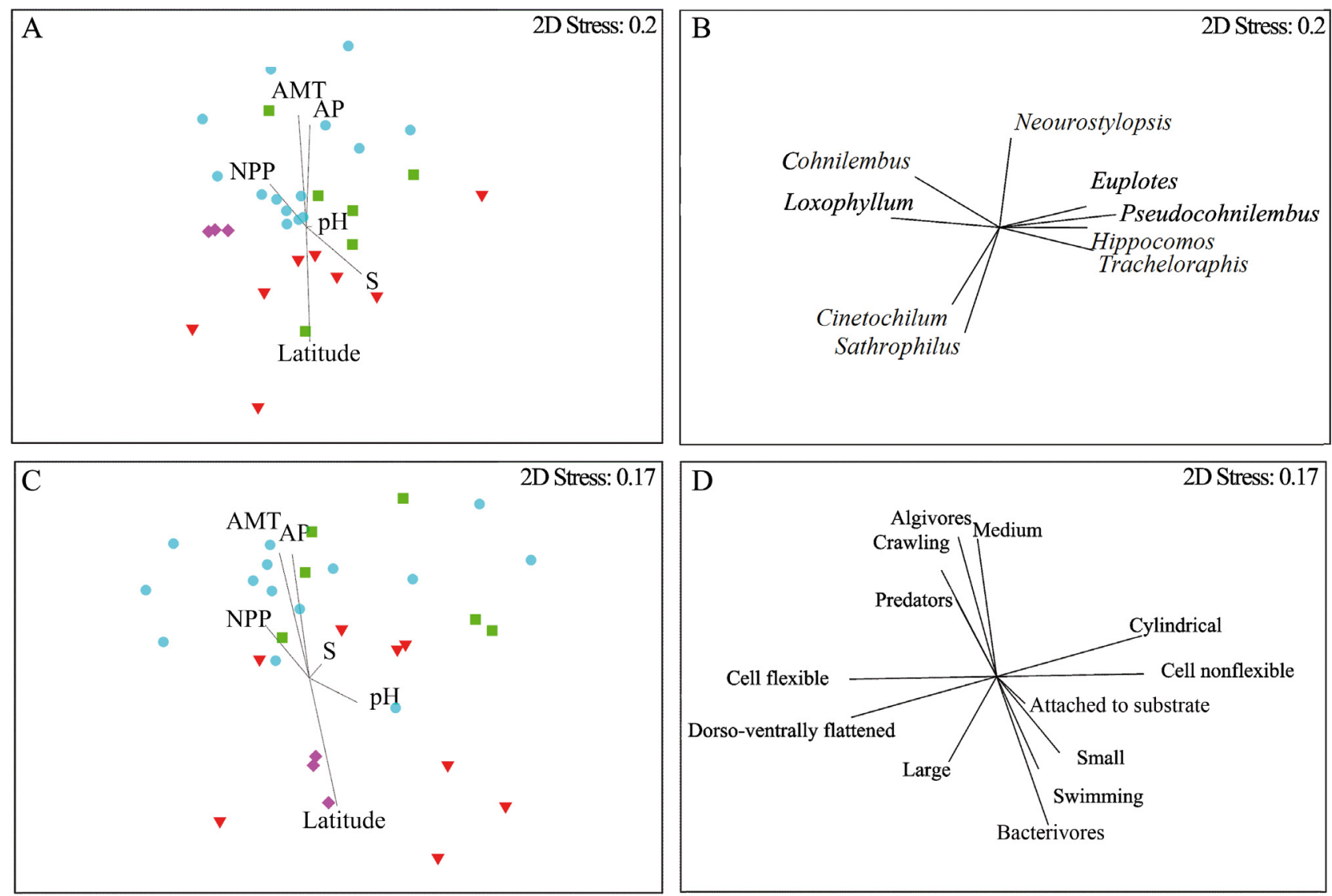

Fig. 2. Non-metric multidimensional scaling (nMDS) ordination plots of benthic ciliate communities along the coast of China based on $(A, B)$ species composition and $(C, D)$ trait composition. Panels A and $C$ also show environmental variables. The length and direction of each vector in B and D indicate the strength and significance of the relationship between typical genera with correlation coefficients $>0.5$ and axes (B) or traits and axes (D). AMT: annual mean temperature; AP: annual precipitation; NPP: net primary productivity; S: salinity 
Table 3. Effects of spatial and environmental variables on the species or trait composition of benthic ciliates along the coast of China analyzed by redundancy analysis (RDA). The p-values were calculated from a Monte Carlo test with 999 permutations $(p<0.01) .(-)$ : Variables not selected by forward selection; NPP: net primary productivity

\begin{tabular}{|lcccc|}
\hline & $\begin{array}{c}\text { Species composition } \\
\mathrm{R}^{2}(\%)\end{array}$ & $\begin{array}{c}\text { Tdrait composition } \\
\text { A }\end{array}$ & $\begin{array}{c}\text { R } \\
\mathrm{R}^{2}(\%)\end{array}$ & Adj R ${ }^{2}(\%)$ \\
\hline Habitat type & 17.6 & 8.4 & - & - \\
Salinity & 5.7 & 2.4 & - & - \\
pH & - & - & - & - \\
NPP & - & - & - & - \\
Latitude & 5.7 & 2.5 & 21.3 & 18.5 \\
\hline
\end{tabular}

\subsection{Patterns of trait composition}

Similar to species composition, trait composition mainly differed significantly among different habitat types (PERMANOVA, main test, $\mathrm{p}=0.001$; Fig. 2C, Table 2), while only the difference between the South sandy beach and mangrove was not significant (Table 2).

The nMDS plot showed clear heterogeneity in dispersions for sites from different habitat types, with salt marsh having markedly smaller dispersion than the other 3 habitat types (Fig. 2C). The test for heterogeneity was also statistically significant in the PERMDISP analysis (Table S2 in Supplement 2). In addition, spatial and climate variables correlated strongly with trait composition on nMDS axis 2, which separated mangrove and South sandy beach from North sandy beach and salt marsh (Fig. 2C). A vector overlay of Pearson correlations of functional traits with the axes is shown in Fig. 2D. The trait categories for the small, swimming and bacterivore taxa were positively correlated with North sandy beach and salt marsh, while medium, crawling, algivores and predators were positively correlated with mangrove and South sandy beach (Fig. 2D).

The results from RDA revealed that the trait composition was only related significantly to latitude among all the variables (Table 3). The fraction of the variance explained by latitude on trait composition was $18.5 \%\left(\operatorname{Adj} \mathrm{R}^{2}\right)$.

For body size, medium size was negatively correlated with latitude $\left(\mathrm{R}^{2}=0.36, \mathrm{p}<0.01\right)$ while large size was positively correlated with latitude $\left(\mathrm{R}^{2}=0.28\right.$, $\mathrm{p}<0.01$; Fig. 3). For feeding type, bacterivores were positively correlated with latitude $\left(\mathrm{R}^{2}=0.44, \mathrm{p}<0.01\right)$ while algivores were negatively correlated with latitude $\left(\mathrm{R}^{2}=0.31, \mathrm{p}<0.01\right.$; Fig. 3$)$. For mobility, swimming taxa were positively correlated with latitude
$\left(\mathrm{R}^{2}=0.36, \mathrm{p}<0.01\right)$ while crawling taxa were negatively correlated with latitude $\left(\mathrm{R}^{2}=0.41, \mathrm{p}<0.01\right.$; Fig. 3). For body form and cell flexibility, we found no significant correlations with latitude.

\subsection{Patterns in functional diversity (FDiv)}

According to GLM, FDiv of benthic ciliates was significantly $(p<0.05$ ) related only to latitude, but the most parsimonious model also included $\mathrm{pH}$ and habitat type (Table 4). FDiv showed a significant positive correlation with latitude $\left(\mathrm{R}^{2}=0.27, \mathrm{p}<0.01\right.$; Fig. 4).

\section{DISCUSSION}

\subsection{Species and trait composition}

Based on PERMDISP analysis, the heterogeneity of both species and trait composition varied considerably between salt marsh and the other 3 habitat types (Table S2). Due to our unbalanced study design, i.e. different numbers of study sites among the 4 habitat types, the detection of differences in centroids among habitat types can be affected by the differences in within-group dispersions (Anderson \& Walsh 2013). However, Anderson \& Walsh (2013) pointed out that if the group with the larger dispersions also has a larger number of samples, the results of a PERMANOVA can be conservative. In our study, salt marsh had a smaller number of samples and smaller dispersion compared with the other 3 habitat types. Moreover, a clear visual pattern of the separation of these sites can be observed in the nMDS plot (Fig. 2A,C). Thus, the difference in centroids of these habitat types can be verified.

Furthermore, we evaluated the relative importance of environmental and spatial factors for variation in benthic ciliate community composition along the coast of China, by adopting both trait-based and more traditional morphological data. RDA showed that 2 environmental variables, i.e. habitat type and salinity, and latitude were the main drivers of species composition, with environmental variables explaining more variation than latitude. Our finding agrees with the notion that microbial species composition is jointly driven by local environmental factors and spatial or climatic variables, but local environment explains more variance due to the high dispersal capacity of microbes and strong species sorting (Langenheder \& Ragnarsson 2007, Soininen et al. 2007, Verleyen et al. 2009, Jyrkänkallio Mikkola et al. 

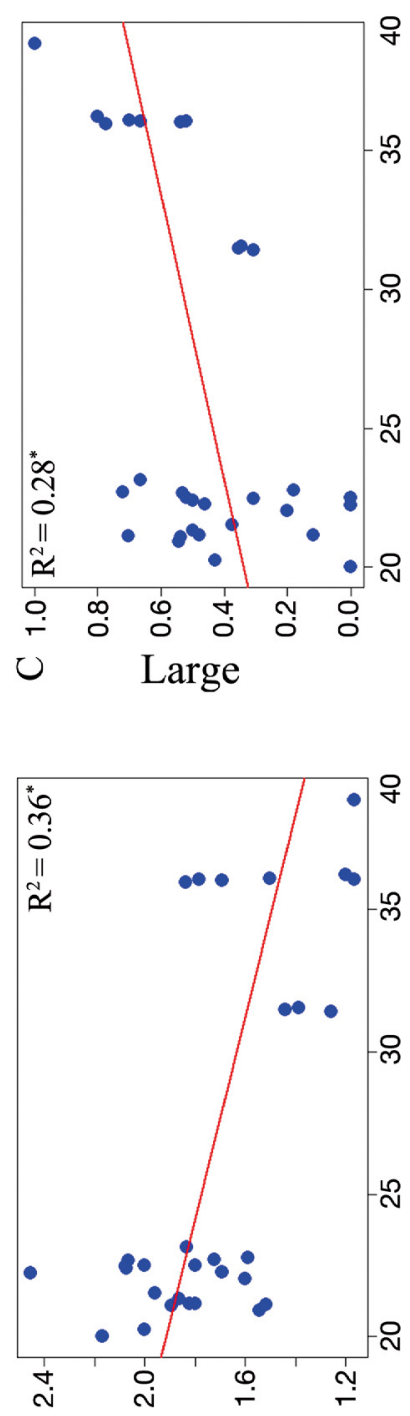

$\infty \quad$ Medium

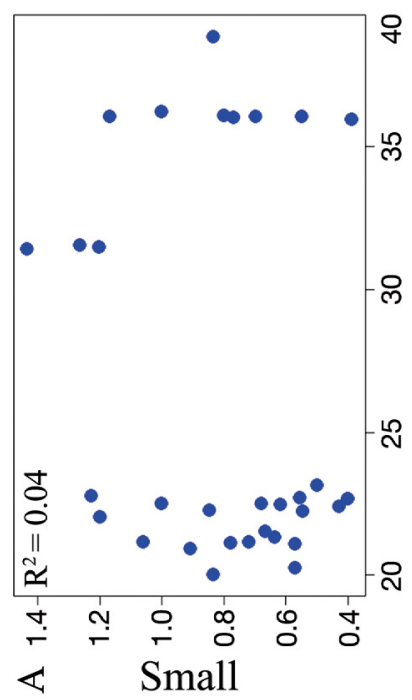

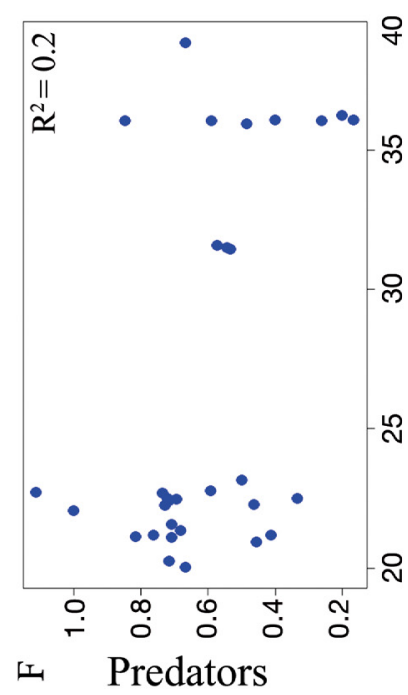
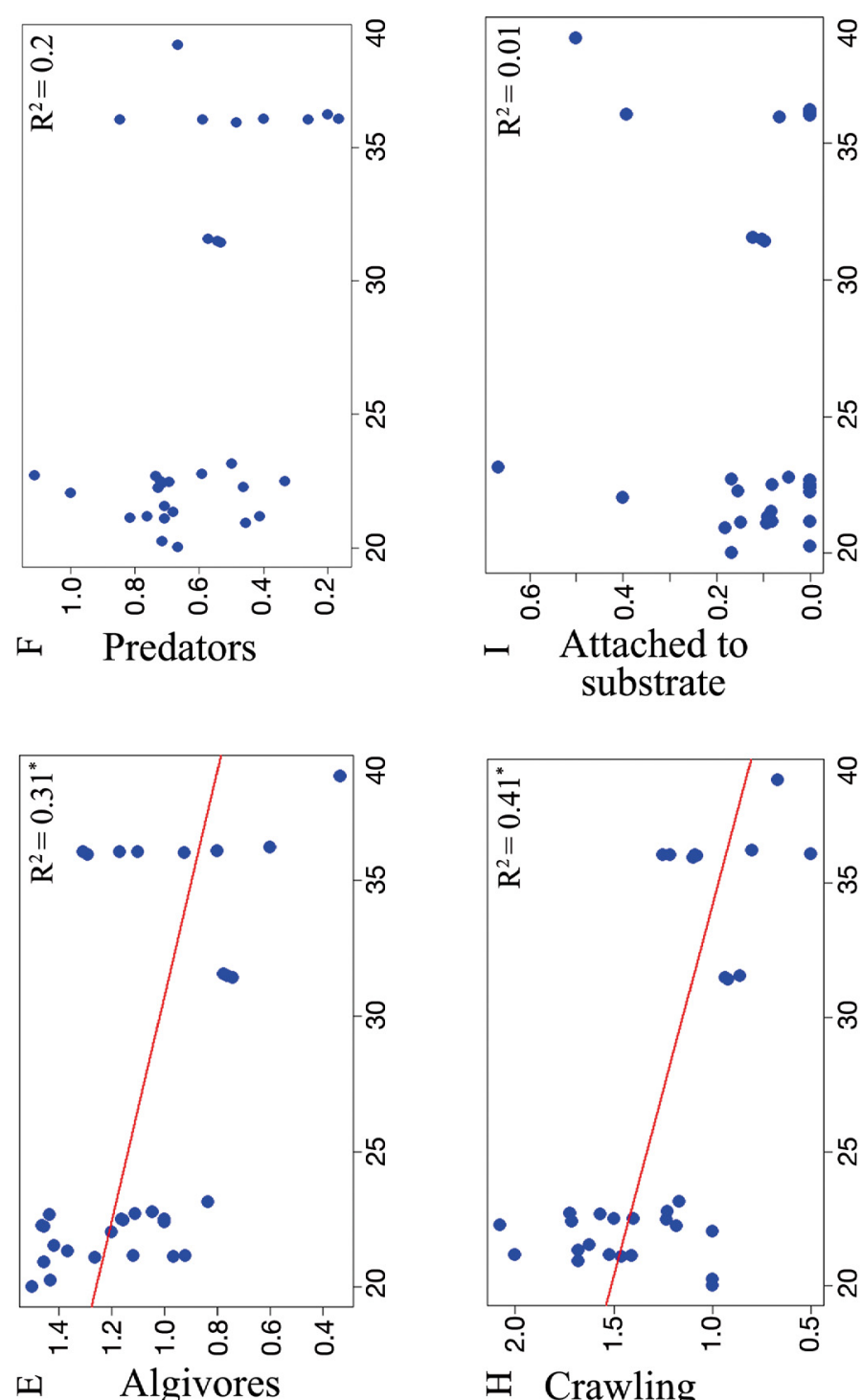

되 Algivores

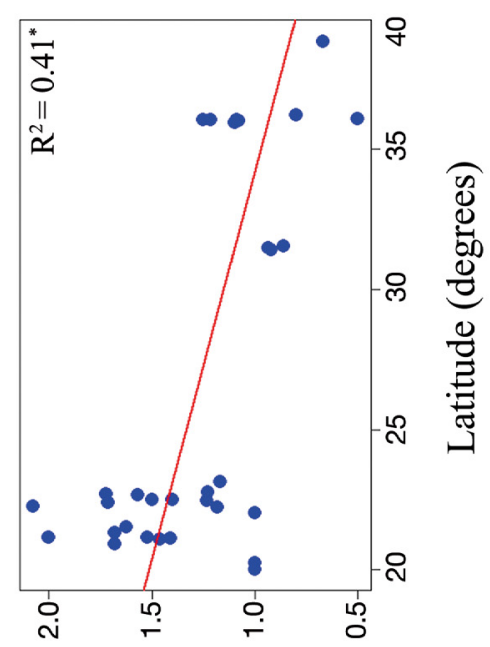

I Crawling
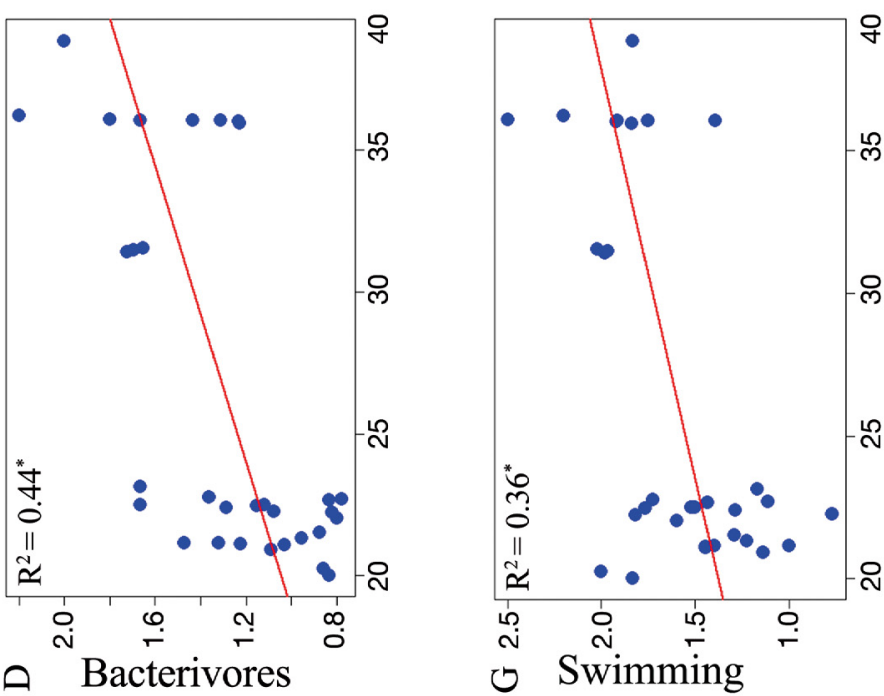
Table 4. ANOVA output of the minimal adequate model showing how environmental and spatial variables affect the functional diversity (FDiv) of benthic ciliates along the coast of China. Significant effect is marked in bold $(p<0.01)$

\begin{tabular}{|llccccc|}
\hline Response variable & Predictor & df & SS & MS & $F$ & p \\
\hline FDiv & Latitude & 1 & 0.0034 & 0.0034 & 12.416 & $\mathbf{0 . 0 0 2}$ \\
& pH & 1 & 0.0003 & 0.0003 & 0.948 & 0.340 \\
& Habitat type & 3 & 0.0020 & 0.0007 & 2.511 & 0.082 \\
& Residuals & 25 & 0.0067 & 0.0003 & & \\
\hline
\end{tabular}

findings are consistent with the idea that local environmental conditions have important effects on taxonomical composition (Hawkins et al. 2000, Tolonen et al. 2017).

However, we found that the trait composition of ciliate communities was mainly driven by spatial or climatic variables at this regional study scale. Similar findings were reported in a study on trait composition of testate

2017). We also found that habitat type had the strongest effect on shaping benthic ciliate species composition. Previous studies on diatoms, bacteria and fish also showed that habitat type explained a larger amount of variation in community composition than local environmental, mainly chemical variables (Drenovsky et al. 2010, Ers et al. 2012, Jyrkänkallio Mikkola et al. 2017). Jyrkänkallio Mikkola et al. (2017) suggested that habitat type might reflect the effects of some unmeasured variables. For example, the sediment grain size is typically one of the most important factors in shaping benthic ciliate community structure (Azovsky \& Mazei 2005, 2018, Hamels et al. 2005, Burkovsky \& Mazei 2010). Unfortunately, we lacked grain size data for most of the original data sources that we collected. Therefore, we use the habitat type as proxies for the unmeasured variables, including sediment grain size, in explaining community variation.

Salinity was also an important factor in determining coastal benthic ciliate species composition. This is congruent with previous studies, which reported the importance of salinity in shaping coastal and estuarine ciliate communities (Kchaou et al. 2009, Sun et al. 2017, Xu et al. 2018a). Therefore, in general, our

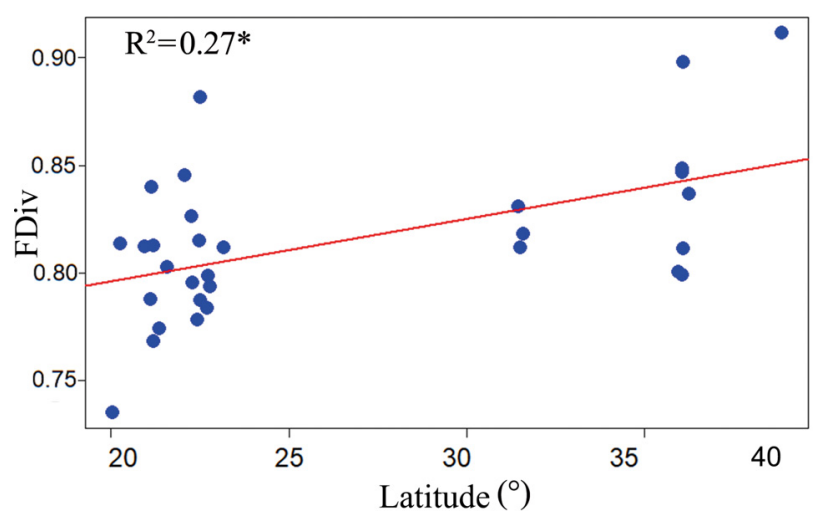

Fig. 4. Relationships between latitude and functional diversity (FDiv) of benthic ciliates along the coast of China; ${ }^{*} \mathrm{p}<0.01$ amoebae, with a stronger correlation with spatial variables compared to environmental factors (Fournier et al. 2016). However, a study on diatom communities found that local environmental variables had stronger effects on trait composition compared to spatial factors (Soininen et al. 2016). We think this relationship depends on the traits chosen in the analyses. The traits of the diatoms used in the analyses by Soininen et al. (2016) included acid tolerance and nitrogenfixing ability, which could be closely related to local environmental conditions, such as $\mathrm{pH}$ and the form and concentration of nitrogen. However, the traits of the ciliates analyzed in our study include morphological characteristics (body size, degree of flexibility and body form) and behavior (feeding and mobility), which may not be as directly linked to local environmental factors, but also to spatial or climatic variables. A study on copepod trait distributions also revealed clear spatial patterns of body size, which exhibited a strong positive trend with latitude (Brun et al. 2016). Kissling et al. (2012) revealed a latitudinal gradient in species richness for different feeding preferences of birds due to the distribution of food resources. Here, we detected significant correlations between latitude and several traits of marine benthic ciliates (Fig. 3). Based on our findings, the latitudinal gradient of body size showed a decreasing trend in medium sized species towards high latitudes, and the opposite trend in large-sized species (Fig. 3), leading to a positive correlation between body size and latitude. Considering the strong covariation between temperature and latitude, we suggest that temperature plays an important role in driving this spatial pattern. In fact, Horne et al. (2016) also pointed out that temperature is the dominant explanatory variable of the spatial patterns in body size of copepods. Moreover, Atkinson et al. (2003) found a significant negative trend between temperature and body size across all protist taxa through a meta-analysis, which agrees with our findings here.

Spatial patterns of feeding type can be more directly linked to the distribution of food resources. 
Since chlorophyll concentrations correlate positively with temperature, it is not surprising to find a change in feeding type composition from bacterivorous to herbivorous ciliates towards lower latitudes (Fig. 3). The mobility trait also exhibited a changing trend from swimming to crawling types with decreasing latitude (Fig. 3). We think this is because the swimming type co-varied with bacterivores, while the crawling type co-varied with algivores. The typical bacterivores found at the North sandy beach included Cinetochilum, Sathrophilus and Hippocomos, which are all scuticociliates and are classified as being the swimming movement type, while the typical algivores from the South sandy beach and mangroves included genera belonging to Spirotrichea and Phyllopharyngea (crawling types).

We further found that benthic ciliate communities from the South sandy beach and mangrove habitats shared a large number of species and traits, although these 2 habitat types differed fundamentally. Since all of the South sandy beach sampling sites were located close to mangrove habitat, we suggest the reason for this is the high dispersal ability of ciliates in a marine system. It is likely that their community structure at adjacent localities is highly influenced by mass effects, which means that within a certain geographic distance, individuals could also occur temporarily in less favorable habitats, resulting in spatially homogenized communities (Pulliam 1988, Leibold et al. 2004). In fact, Heino et al. (2015) suggested that compared with isolated ponds and lakes, the importance of mass effects may be higher in coastal areas and offshore marine systems due to the high physical connection. Based on our findings, mass effects could override the effect of species sorting on shaping ciliate communities in marine coastal systems, especially at smaller spatial extents.

\subsection{Latitudinal gradients in functional diversity}

The functional diversity of ciliates was only significantly correlated with latitude and showed a positive trend. This contradicts the general pattern found in macroorganisms, where species richness and functional diversity peak in (sub)tropical regions (e.g. Stevens et al. 2003, Hillebrand 2004, Kissling et al. 2012, Pease et al. 2012). However, Hillebrand (2004) noted that both the strength and slope of this negative relationship decreased with organism body size, suggesting that such a pattern is weaker in smaller taxa. Soininen (2012) further emphasized that a high dispersal ability and sensitivity to environmental fluc- tuations could lead to substantially different underlying mechanisms for the latitudinal diversity gradients among micro- and macroorganisms. In fact, several exceptions to this classic relationship have been noted in microorganisms. For example, Soininen et al. (2016) found species richness of diatoms to scale positively with latitude, while Passy (2010) reported a U-shaped latitudinal distribution of freshwater diatom richness in the USA, with the peaks located in both subtropical and temperate regions. Furthermore, studies on pelagic tintinnid ciliates and foraminifers revealed a humpshaped relationship, with the maximum species number at $20-30^{\circ}$ north or south rather than at the equator (Rutherford et al. 1999, Dolan et al. 2006), while Vyverman et al. (2007) showed a hump-shaped relationship between latitude and lake diatom richness in the northern hemisphere with the peak located between $55^{\circ}$ and $70^{\circ}$ N. Finally, studies on the global distribution of marine benthic ciliates and heterotrophic flagellates detected no significant correlation between diversity and latitude (Azovsky \& Mazei 2013, Azovsky et al. 2016). In sum, such high variation among study results points to high context-dependency (e.g. in diversity metrics or ecosystem types) in latitudinal richness gradients in microbial taxa.

The potential drivers behind these deviations are manifold. Studies on freshwater diatoms suggested that habitat availability, including lake density and wetland areas, matched closely with species richness gradients (Vyverman et al. 2007, Passy 2010, Soininen et al. 2016), whereas in the present study, no significant correlation between functional diversity and habitat types was detected. Moreover, we found that salinity was not an important factor affecting the functional diversity of ciliates. A study on global marine benthic ciliates found a significant negative relationship between salinity and species richness (Azovsky \& Mazei 2013); however, the study did not consider functional diversity. As a result of functional redundancy, the patterns in species richness and functional diversity do not always follow the same trend (Villéger et al. 2010, Fournier et al. 2012, Xu et al. 2018a). In the present study, climatic variables strongly covaried with latitude; thus, climate is a potential predictor of benthic ciliate functional diversity along the coast of China. The correlations of species richness and functional diversity with climatic variables have been widely reported from macro- to microorganisms, such as birds, soil microbes and foraminiferans (Rutherford et al. 1999, Fuhrman et al. 2008, Kissling et al. 2012). For example, Fernández et al. (2009) reported that temperature was the most important environmental variable showing a clear and con- 
sistent relationship with species richness, but with opposite effects on different taxa. They found a positive relationship for planktotrophic marine species, while a negative relationship was found for directly developing marine benthic species (Fernández et al. 2009). Species-specific temperature adaptation among different ciliate groups affects their reproduction and growth rates at different temperatures (Müller \& Geller 1993, Weisse et al. 2001), and therefore, higher temperatures at lower latitudes may confine the distribution of certain groups of ciliates. We found 11 genera of the karyorelictean ciliates in the North sandy beach habitat, but only 2 genera in the South sandy beach and 3 genera in mangrove habitats. Most species within Karyorelictea possess special traits such as giant body size (200-2000 $\mu \mathrm{m}$ body length), e.g. Geleia, Kentrophoros and Trachelocercids, and an extremely flattened body form, e.g. Remanella, Cryptopharynx and Apocryptopharynx. Since the FDiv index measures functional divergence, we think that the reduction of certain groups of ciliates in southern China, such as Karyorelictea, would have an impact on FDiv, leading to a decreasing trend of FDiv towards lower latitudes. Similar findings were also reported in a study of the global distribution of marine benthic heterotrophic flagellates, with lower taxonomic diversity in warm regions compared with temperate and polar zones (Azovsky et al. 2016). Therefore, whether this positive relationship between functional or taxonomical diversity and latitude exists in other groups of microbial eukaryotes needs to be verified in future studies.

\section{CONCLUSIONS}

Collectively, our results indicate that benthic ciliate community composition varies substantially along the coast of China in response to environmental and spatial or climate variables. Species composition was driven by both environmental factors and latitude, with the former explaining more variation than the latter, while trait composition was only significantly correlated with latitude. Moreover, functional diversity also exhibited a significant trend of increasing towards higher latitudes. Since climatic variables strongly covary with latitude, we postulated that temperature is the main factor driving the trait composition and functional diversity of benthic ciliates along the coast of China. Our findings support that combining analyses of taxonomical and functional trait data can give more insights into microbial biogeography in marine ecosystems.
Acknowledgements. We are grateful to Prof. Weibo Song (Laboratory of Protozoology, Institute of Evolution \& Marine Biodiversity, Ocean University of China) for providing original records. We thank Dr. Xinpeng Fan (School of Life Sciences, East China Normal University) for his opinions on the trait matrix of ciliates. This study was supported by the National Key R\&D Program of China (2017YFC0506001; 2016YFE0133700) and the Natural Science Foundation of China (31601843)

\section{LITERATURE CITED}

Anderson MJ, Walsh DC (2013) PERMANOVA, ANOSIM, and the Mantel test in the face of heterogeneous dispersion: What null hypothesis are you testing? Ecol Monogr 83:557-574

Anderson MJ, Gorley RN, Clarke KR (2008) PERMANOVA+ for PRIMER: guide to software and statistical methods. PRIMER-E, Plymouth

Atkinson D, Ciotti BJ, Montagnes DJ (2003) Protists decrease in size linearly with temperature: ca. $2.5 \%{ }^{\circ} \mathrm{C}^{-1}$. Proc R Soc B 270:2605-2611

Azovsky A, Mazei Y (2005) Distribution and community structure of benthic ciliates in the North Eastern part of the Black Sea. Protistology 4:83-90

Azovsky A, Mazei Y (2013) Do microbes have macroecology? Large scale patterns in the diversity and distribution of marine benthic ciliates. Glob Ecol Biogeogr 22: 163-172

Azovsky A, Mazei Y (2018) Diversity and distribution of free-living ciliates from high-Arctic Kara Sea sediments. Protist 169:141-157

Azovsky A, Tikhonenkov D, Mazei Y (2016) An estimation of the global diversity and distribution of the smallest eukaryotes: biogeography of marine benthic heterotrophic flagellates. Protist 167:411-424

Baas-Becking LGM (1934) Geobiologie of inleiding tot de milieukunde. W.P. Van Stockum \& Zoon, The Hague

* Barton AD, Dutkiewicz S, Flierl G, Bragg J, Follows MJ (2010) Patterns of diversity in marine phytoplankton. Science 327:1509-1511

*Bun P, Payne MR, Kiørboe T (2016) Trait biogeography of marine copepods-an analysis across scales. Ecol Lett 19: 1403-1413

Burkovsky I, Mazei Y (2010) Long-term dynamics of marine interstitial ciliate community. Protistology 6:147-172

Calow P (1987) Towards a definition of functional ecology. Funct Ecol 1:57-61

* Chytrý M, Lososová Z, Horsák M, Uher B and others (2012) Dispersal limitation is stronger in communities of microorganisms than macroorganisms across Central European cities. J Biogeogr 39:1101-1111

Dolan JR, Lemee R, Gasparini S, Mousseau L, Heyndrickx C (2006) Probing diversity in the plankton: using patterns in tintinnids (planktonic marine ciliates) to identify mechanisms. Hydrobiologia 555:143

*Drenovsky RE, Steenwerth KL, Jackson LE, Scow KM (2010) Land use and climatic factors structure regional patterns in soil microbial communities. Glob Ecol Biogeogr 19:27-39

Er s T, Sály P, Takács P, Specziár A, Bíró P (2012) Temporal variability in the spatial and environmental determinants of functional metacommunity organizationstream fish in a human modified landscape. Freshw Biol 57:1914-1928 
Fenchel T (1967) The ecology of marine microbenthos I. The quantitative importance of ciliates as compared with metazoans in various types of sediments. Ophelia 4: 121-137

Fernández M, Astorga A, Navarrete SA, Valdovinos C, Marquet PA (2009) Deconstructing latitudinal species richness patterns in the ocean: Does larval development hold the clue? Ecol Lett 12:601-611

Fierer N, Jackson RB (2006) The diversity and biogeography of soil bacterial communities. Proc Natl Acad Sci USA 103:626-631

Finlay BJ, Esteban GF, Fenchel T (1996) Global diversity and body size. Nature 383:132-133

* Finlay BJ, Esteban GF, Olmo JL, Tyler PA (1999) Global distribution of free living microbial species. Ecography 22: 138-144

Foissner W (1998) An updated compilation of world soil ciliates (Protozoa, Ciliophora), with ecological notes, new records, and descriptions of new species. Eur J Protistol 34:195-235

Foissner W (1999) Protist diversity: estimates of the nearimponderable. Protist 150:363-368

Fournier B, Malysheva E, Mazei Y, Moretti M, Mitchell EA (2012) Toward the use of testate amoeba functional traits as indicator of floodplain restoration success. Eur J Soil Biol 49:85-91

* Fournier B, Coffey EE, van der Knaap WO, Fernández LD, Bobrov A, Mitchell EA (2016) A legacy of human induced ecosystem changes: Spatial processes drive the taxonomic and functional diversities of testate amoebae in sphagnum peatlands of the Galápagos. J Biogeogr 43:533-543

Fuhrman JA, Steele JA, Hewson I, Schwalbach MS, Brown MV, Green JL, Brown JH (2008) A latitudinal diversity gradient in planktonic marine bacteria. Proc Natl Acad Sci USA 105:7774-7778

Green JL, Bohannan BJ, Whitaker RJ (2008) Microbial biogeography: from taxonomy to traits. Science 320: 1039-1043

* Gusmao JB, Brauko KM, Eriksson BK, Lana PC (2016) Functional diversity of macrobenthic assemblages decreases in response to sewage discharges. Ecol Indic 66:65-75

Hamels I, Muylaert K, Sabbe K, Vyverman W (2005) Contrasting dynamics of ciliate communities in sandy and silty sediments of an estuarine intertidal flat. Eur J Protistol 41:241-250

Hawkins CP, Norris RH, Gerritsen J, Hughes RM, Jackson SK, Johnson RK, Stevenson RJ (2000) Evaluation of the use of landscape classifications for the prediction of freshwater biota: synthesis and recommendations. J N Am Benthol Soc 19:541-556

Keino J, Tolkkinen M, Pirttilä AM, Aisala H, Mykrä H (2014) Microbial diversity and community-environment relationships in boreal streams. J Biogeogr 41:2234-2244

Heino J, Melo AS, Siqueira T, Soininen J, Valanko S, Bini LM (2015) Metacommunity organisation, spatial extent and dispersal in aquatic systems: patterns, processes and prospects. Freshw Biol 60:845-869

* Hijmans RJ, Cameron SE, Parra JL, Jones PG, Jarvis A (2005) Very high resolution interpolated climate surfaces for global land areas. Int J Climatol 25:1965-1978

Hillebrand $H$ (2004) On the generality of the latitudinal diversity gradient. Am Nat 163:192-211

Horne CR, Hirst AG, Atkinson D, Neves A, Kiørboe T (2016) A global synthesis of seasonal temperature-size responses in copepods. Glob Ecol Biogeogr 25:988-999
Hu X, Lin X, Song W (2019) Ciliate atlas: species found in the South China Sea. Science Press, Beijing

* Imhoff ML, Bounoua L, Ricketts T, Loucks C, Harriss R, Lawrence WT (2004) Global patterns in human consumption of net primary production. Nature 429:870-873

Jyrkänkallio Mikkola J, Meier S, Heino J, Laamanen T and others (2017) Disentangling multi scale environmental effects on stream microbial communities. J Biogeogr 44: 1512-1523

KKhaou N, Elloumi J, Drira Z, Hamza A, Ayadi H, Bouain A, Aleya L (2009) Distribution of ciliates in relation to environmental factors along the coastline of the Gulf of Gabes, Tunisia. Estuar Coast Shelf Sci 83:414-424

Kissling WD, Sekercioglu CH, Jetz W (2012) Bird dietary guild richness across latitudes, environments and biogeographic regions. Glob Ecol Biogeogr 21:328-340

Laliberté E, Legendre P, Shipley B (2014) FD: measuring functional diversity from multiple traits, and other tools for functional ecology. R package version 1.0-1. https:// cran.r-project.org/src/contrib/Archive/FD/

Langenheder S, Ragnarsson H (2007) The role of environmental and spatial factors for the composition of aquatic bacterial communities. Ecology 88:2154-2161

*aureto LMO, Cianciaruso MV, Samia DSM (2015) Functional diversity: an overview of its history and applicability. J Nat Conserv 13:112-116

K Leibold MA, Holyoak M, Mouquet N, Amarasekare P and others (2004) The metacommunity concept: a framework for multi scale community ecology. Ecol Lett 7:601-613

Lynn D (2008) The ciliated protozoa: characterization, classification, and guide to the literature. Springer Science \& Business Media, Dordrecht

*Martiny JBH, Bohannan BJM, Brown JH, Colwell RK and others (2006) Microbial biogeography: putting microorganisms on the map. Nat Rev Microbiol 4:102-112

Martiny JBH, Eisen JA, Penn K, Allison SD, Horner-Devine MC (2011) Drivers of bacterial $\beta$-diversity depend on spatial scale. Proc Natl Acad Sci USA 108:7850-7854

*McGill BJ, Enquist BJ, Weiher E, Westoby M (2006) Rebuilding community ecology from functional traits. Trends Ecol Evol 21:178-185

Müller H, Geller W (1993) Maximum growth rates of aquatic ciliated protozoa: the dependence on body size and temperature reconsidered. Arch Hydrobiol 126:315-327

*Passy SI (2010) A distinct latitudinal gradient of diatom diversity is linked to resource supply. Ecology 91: $36-41$

*PPease AA, González-Díaz AA, Rodiles Hernández R, Winemiller KO (2012) Functional diversity and trait-environment relationships of stream fish assemblages in a large tropical catchment. Freshw Biol 57:1060-1075

* Peres-Neto PR, Legendre P, Dray S, Borcard D (2006) Variation partitioning of species data matrices: estimation and comparison of fractions. Ecology 87:2614-2625

* Petchey OL, Gaston KJ (2006) Functional diversity: back to basics and looking forward. Ecol Lett 9:741-758

* Pratt JR, Cairns J (1985) Functional groups in the Protozoa: roles in differing ecosystems. J Protozool 32:415-423

* Pulliam HR (1988) Sources, sinks, and population regulation. Am Nat 132:652-661

Rutherford S, D'Hondt S, Prell W (1999) Environmental controls on the geographic distribution of zooplankton diversity. Nature 400:749-753

Soininen J (2012) Macroecology of unicellular organisms patterns and processes. Environ Microbiol Rep 4:10-22 
Soininen J, McDonald R, Hillebrand H (2007) The distance decay of similarity in ecological communities. Ecography 30:3-12

Soininen J, Korhonen JJ, Karhu J, Vetterli A (2011) Disentangling the spatial patterns in community composition of prokaryotic and eukaryotic lake plankton. Limnol Oceanogr 56:508-520

Soininen J, Jamoneau A, Rosebery J, Passy SI (2016) Global patterns and drivers of species and trait composition in diatoms. Glob Ecol Biogeogr 25:940-950

Song W, Warren A, Hu X (2009) Free-living ciliates in the Bohai and Yellow Seas, China: supported by the Darwin Initiative Programme. Science Press, Beijing

Stevens RD, Cox SB, Strauss RE, Willig MR (2003) Patterns of functional diversity across an extensive environmental gradient: vertebrate consumers, hidden treatments and latitudinal trends. Ecol Lett 6:1099-1108

Sun P, Huang L, Xu D, Huang B, Chen N, Warren A (2017) Marked seasonality and high spatial variation in estuarine ciliates are driven by exchanges between the 'abundant' and 'intermediate' biospheres. Sci Rep $7: 9494$

Tolonen KE, Leinonen $\mathrm{K}$, Marttila H, Erkinaro J, Heino J (2017) Environmental predictability of taxonomic and functional community composition in high latitude streams. Freshw Biol 62:1-16

* Verleyen E, Vyverman W, Sterken M, Hodgson DA and others (2009) The importance of dispersal related and local

Editorial responsibility: Erik Kristensen,

Odense, Denmark factors in shaping the taxonomic structure of diatom metacommunities. Oikos 118:1239-1249

*Villéger S, Mason NWH, Mouillot D (2008) New multidimensional functional diversity indices for a multifaceted framework in functional ecology. Ecology 89:2290-2301

Villéger S, Miranda JR, Hernández DF, Mouillot D (2010) Contrasting changes in taxonomic vs. functional diversity of tropical fish communities after habitat degradation. Ecol Appl 20:1512-1522

*Villéger S, Novack-Gottshall PM, Mouillot D (2011) The multidimensionality of the niche reveals functional diversity changes in benthic marine biotas across geological time. Ecol Lett 14:561-568

* Vyverman W, Verleyen E, Sabbe K, Vanhoutte K and others (2007) Historical processes constrain patterns in global diatom diversity. Ecology 88:1924-1931

* Weisse T, Karstens N, Meyer VCL, Janke L, Lettner S, Teichgräber K (2001) Niche separation in common prostome freshwater ciliates: the effect of food and temperature. Aquat Microb Ecol 26:167-179

Xu Y, Fan X, Warren A, Zhang L, Xu H (2018a) Functional diversity of benthic ciliate communities in response to environmental gradients in a wetland of Yangtze Estuary, China. Mar Pollut Bull 127:726-732

* Xu Y, Stoeck T, Forster D, Ma Z, Zhang L, Fan X (2018b) Environmental status assessment using biological traits analyses and functional diversity indices of benthic ciliate communities. Mar Pollut Bull 131:646-654

Submitted: May 20, 2019; Accepted: July 25, 2019 Proofs received from author(s): September 9, 2019 